\title{
Occupations, work characteristics and common mental disorder
}

\author{
S. A. Stansfeld ${ }^{1 *}$, C. Pike ${ }^{1}$, S. McManus ${ }^{2}$, J. Harris ${ }^{2}$, P. Bebbington ${ }^{3}$, T. Brugha ${ }^{4}$, A. Hassiotis ${ }^{3}$, \\ R. Jenkins ${ }^{5}$, H. Meltzer ${ }^{4}$, P. Moran ${ }^{6}$ and C. Clark ${ }^{1}$ \\ ${ }^{1}$ Centre for Psychiatry, Wolfson Institute of Preventive Medicine, Barts and The London School of Medicine and Dentistry, Queen Mary \\ University of London, UK \\ ${ }^{2}$ National Centre for Social Research, London, UK \\ ${ }^{3}$ UCL Department of Mental Health Sciences, London, UK \\ ${ }^{4}$ Department of Health Sciences, College of Medicine, Biological Sciences and Psychology, University of Leicester, Leicester, UK \\ ${ }^{5}$ WHO Collaborating Centre for Research and Training in Mental Health and Section of Mental Health Policy, Health Service and Population \\ Research, Institute of Psychiatry, King's College London, London, UK \\ ${ }^{6}$ Health Service and Population Research, Institute of Psychiatry, King's College London, London, UK
}

Background. The present study aimed to assess the prevalence of common mental disorders (CMDs) by occupation in a representative sample of the English adult population. Another aim was to examine whether the increased risk of CMD in some occupations could be explained by adverse work characteristics.

Method. We derived a sample of 3425 working-age respondents from the Adult Psychiatric Morbidity Survey 2007. Occupations were classified by Standard Occupational Classification group, and CMD measured by the Revised Clinical Interview Schedule. Job characteristics were measured by questionnaire, and tested as explanatory factors in associations of occupation and CMD.

Results. After adjusting for age, gender, housing tenure and marital status, caring personal service occupations had the greatest risk of CMD compared with all occupations (odds ratio 1.73, 95\% confidence interval 1.16-2.58). The prevalence of adverse psychosocial work characteristics did not follow the pattern of CMD by occupation. Work characteristics did not explain the increased risk of CMDs associated with working in personal service occupations. Contrary to our hypotheses, adding work characteristics individually to the association of occupation and CMD tended to increase rather than decrease the odds for CMD.

Conclusions. As has been found by others, psychosocial work characteristics were associated with CMD. However, we found that in our English national dataset they could not explain the high rates of CMD in particular occupations. We suggest that selection into occupations may partly explain high CMD rates in certain occupations. Also, we did not measure emotional demands, and these may be important mediators of the relationship between occupation type and CMDs.

Received 3 January 2012; Revised 6 July 2012; Accepted 12 July 2012; First published online 21 August 2012

Key words: Depression, epidemiology, mental disorder, occupation, work.

\section{Introduction}

Rates of common mental disorders (CMDs), largely depression and anxiety, vary by occupation. The specific attributes of certain occupations may be responsible for higher rates of CMDs. There is some consistency across European and North American studies about which occupations are associated with high rates of CMD. People involved in sales, personal

* Address for correspondence: S. A. Stansfeld, Ph.D., Centre for Psychiatry, Old Anatomy Building, Barts and the London School of Medicine and Dentistry, Charterhouse Square, London EC1M 6BQ, UK.

(Email: s.a.stansfeld@qmul.ac.uk) and protective services, teaching, clerical and secretarial, welfare workers, and kitchen and waiting staff seem to be particularly at risk (Eaton et al. 1990; Roberts \& Lee, 1993; Jones et al. 1998; Sanne et al. 2003; Wieclaw et al. 2005; Marchand, 2007; Stansfeld et al. 2011). It is not clear whether there are common factors in the diverse range of occupations associated with a high rate of CMDs. Work characteristics have not previously been studied as an explanation of the differing rates of CMD between occupations.

There have been numerous studies of psychosocial work characteristics and mental health: two metaanalyses have linked job strain to increased risks of depression, and both job strain and effort-reward

The online version of this article is published within an Open Access environment subject to the conditions of the Creative Commons Attribution-NonCommercial-ShareAlike licence $<$ http://creativecommons.org/licenses/by-nc-sa/2.5/ $>$. The written permission of Cambridge University Press must be obtained for commercial re-use. 
imbalance (ERI) to increased risk of CMDs (Stansfeld \& Candy, 2006; Netterstrom et al. 2008), although not all reviewers are convinced of a causal association (Bonde, 2008). Karasek's model proposes that highstrain jobs, involving high demands but low control over how work is carried out, are most detrimental to health (Karasek, 1979; Karasek \& Theorell, 1990). Many studies have found that this combination of work characteristics is highly associated with adverse health outcomes in comparison with low-strain work (low demands/high control) (de Lange et al. 2003; Stansfeld \& Candy, 2006). The job strain model also incorporates social support from colleagues and managers, as this may modify the effect of highstrain work on mental health (Johnson \& Hall, 1988). It may indeed be possible to thrive in high-demand situations as long as there is adequate control and support.

Another influential theory of psychosocial work characteristics suggests that adverse health may result from a mismatch between the efforts and rewards of the work (Siegrist, 1996). Such ERI occurs when the efforts of the work are high but its rewards in terms of being valued by the organization, having good promotion prospects and job security are low. Experiencing ERI can result in disappointment and feelings of not being treated fairly, which in the long term affect physical and mental health (Pikhart et al. 2004). An addition to the model posits that over-commitment to one's job may amplify the association between ERI and mental disorder (Siegrist, 1996; de Jonge, 2000; van Vegchel, 2005).

In an analysis of an earlier national UK survey we found higher than average rates of CMD in sales staff, personal and protective services, managers and administrators, teaching staff, and clerical and secretarial staff (Stansfeld et al. 2011). We speculated that high demand (in particular, emotional demands for personal and protective services and teachers), high job insecurity, low work support, and ERI might explain the higher rates in these occupations. However, in that survey there were no measures of work characteristics, and we were unable to test out these ideas. In the current paper we present data from a new representative national survey, the 2007 Adult Psychiatric Morbidity Survey (APMS 2007). This survey included the Standard Occupational Classification (SOC; Office for National Statistics, 2000) together with the Karasek Job Content Instrument (Karasek, 1979; Karasek \& Theorell, 1990) and the short version of the Effort Reward Imbalance questionnaire (Siegrist et al. 2009). This has allowed us to test for the first time whether psychosocial work characteristics can explain the differing rates of CMD between occupations. We hypothesized that higher rates of CMD in certain occupations would be explained by high demands, low work social support, high job insecurity, and high job strain (high demands and low control) and ERI (high effort and low rewards).

\section{Method}

This paper analyses data from the APMS 2007 (McManus et al. 2009), a stratified probability sampling survey of those aged over 16 years living in private households in England. The survey was carried out as part of the extensive programme of national mental health surveys in Great Britain (Jenkins et al. 2009). The APMS 2007 used structured procedures for identifying psychiatric disorders. It also recorded data on a range of sociodemographic variables, on occupation type and, for the first time, included questions on psychosocial work characteristics. Ethical approval for the APMS 2007 was obtained from the Royal Free Hospital and Medical School Ethics Committee.

\section{Sample}

The APMS 2007 was conducted in two phases. Residential addresses were randomly sampled using the small user Postcode Address File (McManus et al. 2009). Interviewers from the National Centre for Social Research visited the selected locations to identify private households with at least one resident aged over 16 years. The Kish grid method (Kish, 1965) was used to select one person from those eligible in each household to take part in the survey. A total of 13171 households were visited and 57\% (7461) of the eligible participants $(69 \%$ of those successfully contacted) agreed to take part in the phase one survey, which provided the data presented here. There were 4075 refusals, 499 known eligible non-contacts, 471 eligible non-contacts and 664 unable/unproductive contacts. Response rate was lower in the West Midlands, East of England, London, South East and South West, among households with entry barriers and households not owner occupied. Information was collected by professional survey interviewers, using computerassisted personal interviews lasting approximately 90 min. Full details of the sampling procedure and the methods used have been given by McManus et al. (2009).

The analysis in this paper uses the subsample of 3425 respondents who were of working age (16-64 years), had engaged in paid work in the previous week, were not self-employed, and had answered all questions relevant to this analysis. 


\section{Measures}

$C M D$

The Revised Clinical Interview Schedule (Lewis et al. 1992), a standardized clinical psychiatric interview, was used to establish the presence of non-psychotic symptoms of CMD in the past week. Algorithms were then used to derive International Classification of Diseases, Tenth Revision (ICD-10) diagnoses of six specific disorders (generalized anxiety disorder, mixed anxiety and depressive disorder, depressive episode, panic disorder, phobia and obsessivecompulsive disorder). A dichotomous measure of presence or absence of any CMD was derived from the individual diagnoses.

\section{Occupation}

Respondents were asked about the nature of their job: whether it was full or part time, their job title, a description of their role, and whether they had a management or supervisory position. Occupations were classified as one of 371 occupations or 'units', in accordance with the SOC schedule 2000 (Office for National Statistics, 2000). Units are grouped into nine major SOC groups, which broadly classify occupations similar in terms of qualifications, training, skills and experience. Units are further subgrouped into $25 \mathrm{sub}-$ major SOC groups (see Table 1 for the complete classifications).

\section{Work characteristics}

Siegrist's ERI model was measured by the short version of the ERI questionnaire (Siegrist et al. 2009). This involved asking respondents whether they agreed or disagreed on a four- or five-point Likert scale to statements describing the characteristics of their work such as: 'I have constant time pressure due to a heavy work load' and 'people say I sacrifice too much for my job'. Effort was measured by three questions on efforts/demands at work (Cronbach's $\alpha=0.787$ ). Rewards were measured by two questions on job prospects, and four questions measured esteem from colleagues, clients, customers and managers. There were also two questions on job security, and six questions measured over-commitment (Cronbach's $\alpha=0.805)$. More information on the work characteristic items can be found in an unpublished paper by Harris et al. (J. Harris et al. unpublished observations).

A total of six questions, based on the Karasek job strain model, adapted from the Whitehall II study questionnaire (Karasek, 1979; North et al. 1996), assessed the respondents' perceived level of control (two items) (Cronbach's $\alpha=0.731$ ) and support at work (four items) (Cronbach's $\alpha=0.792$ ). The same questions were used to measure both effort and 'demands' for the Karasek job strain model to make up the two orthogonal dimensions of demands and control. Items concerning control consisted of two questions asking respondents to rate on a four-point Likert scale how often they have a choice over how they do their work and what they work on (often/sometimes / seldom/never-almost never). Support questions asked respondents to rate the frequency of support offered by line managers and colleagues on an equivalent scale.

Scores for each item were summed to produce a total score for each individual work characteristic, and respondents were then placed into tertiles representing whether they had high, medium or low scores on each characteristic. Measures of job strain and ERI were derived using these tertiles.

Respondents reporting high efforts and low rewards were assigned to the 'ERI' category, those reporting high demands and low control to the 'job strain' category. Respondents experiencing low effort/ demands and low control were assigned to the 'passive' job category, while those reporting high effort/ demands and high control were allocated to the 'active' job category. People with the most favourable work characteristics, i.e. low effort/demands and high control, formed the 'low strain' category (see Table 2). The job strain and ERI models were shown to have acceptable factorial validity [root mean square error of approximation (RMSEA) <0.08] when tested using confirmatory factor analysis on this dataset (J. Harris et al. unpublished observations).

\section{Alcohol problems}

Alcohol-use disorders were measured by the 10-item Alcohol Use Disorders Identification Test (AUDIT), a widely used indicator of hazardous drinking, scored from 0 to 40 (Saunders et al. 1993). Scores were grouped 0-7 (73.1\%), 8-15 (hazardous use of alcohol, $23.2 \%$ ) and 16-40 (hazardous and harmful to health, $3.7 \%)$

\section{Analysis}

The first step in the analysis was to establish the associations between the major and sub-major SOC groups and CMD, using logistic regression analyses adjusted for age, gender, housing tenure and marital status. Associations between major SOC group and CMD were then tested for interactions with gender, and analyses were re-run stratified by gender if the interaction was significant. The relationship between sub-major SOC group and CMD was not tested for gender interactions because of small group sizes. 
Table 1. Risk for CMD by major SOC groups, unadjusted and adjusted for age, gender, housing tenure and marital status

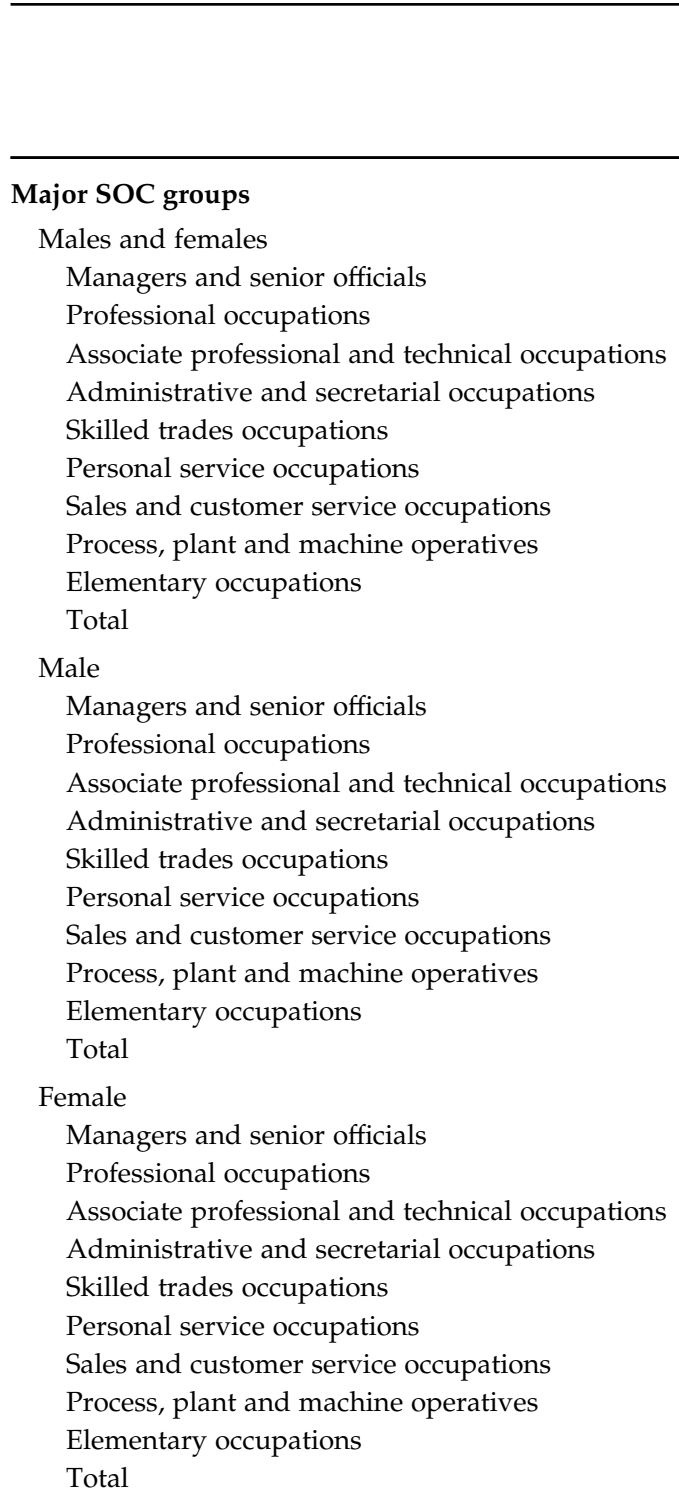

\section{Major SOC group}

Males and females

Associate professional and technical occupations

\begin{tabular}{ll} 
Sample & With CMD \\
$n(\%)$ & $n(\%)$ \\
\hline
\end{tabular}

Risk for CMD,
unadjusted

Risk for CMD

$\mathrm{OR}^{\mathrm{a}}(95 \% \mathrm{CI})$

adjusted

OR $(95 \% \mathrm{CI})$

$558(16.3)$
$450(13.1)$
$560(16.4)$
$372(10.9)$
$312(9.1)$
$282(8.2)$
$273(8.0)$
$243(7.1)$
$374(10.9)$
3425

\section{4 (19.3) \\ 265 (14.4) \\ 265 (14.4) \\ 97 (5.3) \\ 289 (15.7) \\ 57 (3.1) \\ 94 (5.1) \\ 207 (11.3) \\ 209 (11.4)}

1834

$204(12.8)$
$186(11.7)$
$295(18.6)$
$275(17.3)$
$23(1.5)$
$226(14.2)$
$179(11.2)$
$36(2.3)$
$165(10.4)$
1591

1591

$\begin{array}{ll}63(11.3) & 0.75(0.54-1.03) \\ 53(11.7) & 0.79(0.56-1.10) \\ 82(14.7) & 1.06(0.79-1.43) \\ 57(15.4) & 1.13(0.81-1.56) \\ 31(9.8) & 0.64(0.43-0.96) \\ 67(23.9) & 2.07(1.43-2.98)^{*} \\ 47(17.4) & 1.31(0.87-1.98) \\ 18(7.5) & 0.48(0.28-0.81)^{*} \\ 63(16.8) & 1.27(0.88-1.82)\end{array}$

482 (14.1)

28 (7.9)

27 (10.2)

$30(11.2)$

15 (15.9)

$23(7.8)$

$10(18.3)$

$15(15.9)$

12 (5.6)

24 (11.3)

$183(10.0)$

35 (17.3)

$26(13.8)$

$53(17.9)$

42 (15.2)

8 (34.3)

$57(25.3)$

$33(18.2)$

7 (18.5)

$126(23.8)$

299 (18.8)
$0.73(0.46-1.18)$

1.04 (0.64-1.68)

$1.16(0.69-1.96)$

$1.77(0.91-3.46)$

$0.73(0.48-1.13)$

$2.09(0.81-5.33)$

$1.77(0.88-3.56)$

$0.51(0.27-0.94)^{*}$

1.17 (0.66-2.09)

$0.89(0.64-1.32)$

$0.66(0.44-0.99)^{*}$

$0.93(0.67-1.28)$

$0.74(0.52-1.06)$

$2.29(0.96-5.45)$

$1.57(1.04-2.37)^{*}$

$0.95(0.57-1.60)$

$0.98(0.40-2.38)$

$1.40(0.90-2.16)$
$0.81(0.58-1.13)$

$0.83(0.59-1.16)$

$1.01(0.74-1.37)$

$0.92(0.65-1.31)$

$0.91(0.60-1.38)$

$1.62(1.11-2.37)^{*}$

$1.13(0.73-1.73)$

$0.62(0.36-1.06)$

$1.28(0.87-1.87)$

$0.75(0.46-1.20)$

1.07 (0.66-1.75)

$1.18(0.70-2.00)$

$1.81(0.91-3.58)$

$0.74(0.48-1.13)$

$2.02(0.81-5.00)$

$1.68(0.82-3.43)$

$0.52(0.28-0.99)^{*}$

1.06 (0.58-1.95)

$0.88(0.59-1.30)$ $0.66(0.44-0.99)^{*}$ $0.92(0.66-1.27)$ $0.75(0.52-1.07)$ $2.35(0.97-5.68)$ $1.55(1.02-2.36)^{*}$ 0.95 (0.57-1.60) $0.97(0.40-2.36)$ $1.45(0.92-2.28)$ 
Sub-major SOC groups

Males and females

Corporate managers

Managers and proprietors in agriculture and service

$471(13.8)$

$87(2.5)$

$137(4.0)$

$23(0.7)$

Health professionals

Teaching and research professionals

$186(5.4)$

$104(3.0)$

$55(1.6)$

Science and technology associate professionals

$169(4.9)$

$50(1.5)$

$58(1.7)$
$228(6.6)$

Protective service occupations

$279(8.1)$

$93(2.7)$

$15(0.5)$

$145(4.2)$

$74(2.2)$

78 (2.3)

$234(6.8)$

48 (1.4)

$219(6.4)$

$54(1.6)$

132 (3.8)

$112(3.3)$

$94(2.7)$

281 (8.2)

3425

$56(11.9)$
$7(8.1)$
$13(9.6)$
$4(17.9)$
$28(14.8)$
$8(7.7)$
$10(18.3)$
$24(14.1)$
$9(18.0)$
$9(15.6)$
$30(13.3)$
$43(15.5)$
$14(15.1)$
$2(13.3)$
$13(9.0)$
$7(9.3)$
$9(11.7)$
$60(25.8)$
$7(14.8)$
$38(17.5)$
$9(16.7)$
$12(9.3)$
$6(5.4)$
$10(11.1)$
$52(18.7)$
$482(14.1)$

$0.80(0.58-1.12)$

$0.53(0.24-1.19)$

$0.64(0.36-1.14)$

$1.33(0.42-4.20)$

$1.06(0.68-1.66)$

$0.50(0.23-1.07)$

$1.38(0.59-3.21)$

$1.00(0.65-1.56)$

$1.34(0.66-2.74)$

$1.13(0.49-2.61)$

$0.93(0.58-1.51)$

$1.13(0.77-1.66)$

$1.09(0.59-2.03)$

$0.70(0.15-3.39)$

$0.59(0.34-1.02)$

$0.62(0.22-1.73)$

$0.80(0.38-1.70)$

$2.28(1.55-3.35)^{*}$

$1.06(0.36-3.12)$

$1.45(0.97-2.16)$

$1.23(0.52-2.90)$

$0.60(0.32-1.12)$

$0.34(0.13-0.90)$

$0.76(0.34-1.71)$

$1.45(0.97-2.16)$

$0.88(0.63-1.23)$

$0.55(0.25-1.22)$

$0.79(0.43-1.46)$

$1.55(0.49-4.93)$

$0.96(0.61-1.53)$

$0.54(0.25-1.17)$

$1.53(0.67-3.50)$

$0.81(0.51-1.26)$

$1.61(0.78-3.32)$

$1.21(0.51-2.86)$

$0.91(0.56-1.49)$

$1.00(0.67-1.49)$

$0.78(0.41-1.48)$

$0.99(0.23-4.34)$

$0.91(0.52-1.57)$

$0.93(0.34-2.57)$

$0.90(0.43-1.89)$

$1.73(1.16-2.58)^{*}$

$1.01(0.33-3.05)$

$1.36(0.90-2.08)$

$1.06(0.45-2.51)$

$0.73(0.39-1.38)$

$0.47(0.18-1.23)$

0.95 (0.42-2.15)

$1.36(0.90-2.08)$

CMD, Common mental disorder; SOC, Standard Occupational Classification; OR, odds ratio; CI, confidence interval.

Data are given as number of participants (percentage) and as odds ratio $(95 \% \mathrm{CI}$ )

${ }^{\text {a }}$ Odds are given for the major SOC group versus all the other major SOC groups combined.

$* p \leqslant 0.05$. 
Table 2. The prevalence of adverse psychosocial work characteristics by major SOC groups and the odds ${ }^{\mathrm{a}}$ for adverse psychosocial work characteristics by major SOC groups

\begin{tabular}{|c|c|c|c|c|c|c|c|c|c|c|}
\hline & \multicolumn{2}{|c|}{ Job strain ${ }^{\mathrm{b}}$} & \multicolumn{2}{|l|}{$\mathrm{ERI}^{\mathrm{c}}$} & \multicolumn{2}{|c|}{ High job effort/demands } & \multicolumn{2}{|c|}{ Low job security } & \multicolumn{2}{|c|}{ Low social support at work } \\
\hline & $n(\%)$ & $\mathrm{OR}^{\mathrm{a}}(95 \% \mathrm{CI})$ & $n(\%)$ & $\mathrm{OR}^{\mathrm{a}}(95 \% \mathrm{CI})$ & $n(\%)$ & $\mathrm{OR}^{\mathrm{a}}(95 \% \mathrm{CI})$ & $n(\%)$ & $\mathrm{OR}^{\mathrm{a}}(95 \% \mathrm{CI})$ & $n(\%)$ & $\mathrm{OR}^{\mathrm{a}}(95 \% \mathrm{CI})$ \\
\hline \multicolumn{11}{|l|}{ Major SOC groups } \\
\hline \multicolumn{11}{|l|}{ Males and females } \\
\hline Managers and senior officials & $41(8.5)$ & $0.63(0.44-0.91)^{*}$ & $75(14.9)$ & $1.24(0.92-1.66)$ & $314(64.3)$ & $2.58(2.10-3.18)^{* * * *}$ & $136(27.9)$ & $0.84(0.66-1.07)$ & $134(29.4)$ & $1.21(0.95-1.56)$ \\
\hline Professional occupations & $38(8.3)$ & $0.62(0.42-0.92)^{*}$ & $53(10.3)$ & $0.75(0.54-1.04)$ & $242(53.7)$ & $1.50(1.21-1.87)^{* * *}$ & $112(25.0)$ & $0.71(0.55-0.92)^{* *}$ & $91(20.3)$ & $0.69(0.52-0.92)^{*}$ \\
\hline $\begin{array}{l}\text { Associate professional and } \\
\text { technical occupations }\end{array}$ & $73(14.0)$ & $1.22(0.91-1.63)$ & $85(16.4)$ & $1.41(1.04-1.91)^{*}$ & $288(57.0)$ & $1.79(1.45-2.21)^{* * *}$ & $159(32.2)$ & $1.07(0.84-1.37)$ & $23.9(125)$ & $0.87(0.68-1.09)$ \\
\hline $\begin{array}{l}\text { Administrative and } \\
\text { secretarial occupations }\end{array}$ & $43(12.6)$ & $0.96(0.65-1.40)$ & $53(13.4)$ & $0.94(0.68-1.30)$ & $151(42.0)$ & $1.14(0.90-1.45)$ & $115(30.9)$ & $0.99(0.77-1.28)$ & $90(25.1)$ & $1.06(0.81-1.38)$ \\
\hline Skilled trades occupations & $39(16.7)$ & $1.51(1.05-2.18)^{*}$ & $38(15.0)$ & $1.21(0.80-1.83)$ & $105(43.1)$ & $0.92(0.70-1.21)$ & $92(35.6)$ & $1.27(0.95-1.68)$ & $66(24.6)$ & $0.91(0.67-1.23)$ \\
\hline Personal service occupations & $33(11.8)$ & $0.97(0.64-1.46)$ & $28(10.0)$ & $0.74(0.47-1.16)$ & $82(32.1)$ & $0.56(0.42-0.73)^{* * *}$ & $66(23.8)$ & $0.68(0.50-0.93)^{*}$ & $50(19.0)$ & $0.64(0.46-0.89)^{* *}$ \\
\hline $\begin{array}{l}\text { Sales and customer service } \\
\text { occupations }\end{array}$ & $24(9.4)$ & $0.73(0.45-1.20)$ & $18(7.7)$ & $0.54(0.31-0.96)^{*}$ & $53(22.3)$ & $0.32(0.22-0.47)^{* * *}$ & $57(28.3)$ & $0.88(0.62-1.24)$ & $54(28.0)$ & $1.10(0.75-1.61)$ \\
\hline $\begin{array}{l}\text { Process, plant and machine } \\
\text { operatives }\end{array}$ & $37(18.1)$ & $1.67(1.11-2.52)^{*}$ & $24(12.1)$ & $0.93(0.53-1.64)$ & $64(32.1)$ & $0.56(0.38-0.81)^{* *}$ & $80(41.2)$ & $1.63(1.18-2.25)^{* *}$ & $72(36.3)$ & $1.67(1.21-2.33)^{* *}$ \\
\hline Elementary occupations & $38(13.4)$ & $1.14(0.78-1.66)$ & $34(11.4)$ & $0.86(0.58-1.28)$ & $78(25.9)$ & $0.39(0.29-0.52)^{* * * *}$ & $103(36.9)$ & $1.36(1.03-1.78)^{*}$ & $93(31.3)$ & $1.33(1.01-1.76)^{*}$ \\
\hline All major SOC groups ${ }^{\mathrm{d}}$ & 415 (12.1) & & $440(12.8)$ & & $1537(44.9)$ & & 1058 (30.9) & & $895(26.1)$ & \\
\hline
\end{tabular}

SOC, Standard Occupational Classification; ERI, effort-reward imbalance; OR, odds ratio; CI, confidence interval.

Data are given as number of participants (percentage) and as odds ratio $(95 \% \mathrm{CI})$.

a Odds are given for the major SOC group versus all the other major SOC groups combined. The OR give the odds for the category (e.g. high job strain); ERI (high effort/low rewards); high effort/demands; low job security; and low social support versus all other response options combined (e.g. passive/active/low-strain jobs; low effort-low rewards/high effort-high rewards/low effort-high rewards jobs; low- and midlevel of efforts/demands; high and mid-level of job security; high- and mid-level social support).

${ }^{\mathrm{b}}$ Karasek Job Content Instrument (Karasek, 1979; Karasek \& Theorell, 1990).

${ }^{\mathrm{C}}$ Effort Reward Imbalance questionnaire (Siegrist et al. 2009).

d Prevalence of the work characteristic in the complete working sample.

${ }^{*} p \leqslant 0.05,{ }^{* *} p \leqslant 0.01,{ }^{* * *} p \leqslant 0.001$. 
In the next step the prevalence of work characteristics in various SOC groups was examined and the odds of whether each occupation had different levels of adverse work characteristics relative to all occupations was tested. In the third, final step, the associations between the major and sub-major SOC groups and CMD were further adjusted, individually, for job strain, ERI, job demands, job security and social support at work in turn.

Factors confounding the associations between sociodemographic characteristics, work characteristics and CMD were identified by using bivariate logistic regression; sociodemographic characteristics that predicted both adverse work characteristics and independently CMD were adjusted for in the subsequent analyses. Throughout the analysis the overall working sample was used as a reference. All odds ratios (ORs) represent an increase in odds of CMD compared with the overall working sample for models using major and sub-major groups.

Associations between CMD, work characteristics and SOC groups were analysed using SPSS version 16.0 (SPSS, Inc., USA). The complex samples function was used to take account of the weighting procedures. Weights were applied to represent the structure of the national population, and to account for the probability of selection and non-response. Unweighted figures represent the number of interviews conducted, while weighted figures show the relative size of each group in the population. A full description of weighting procedures can be found in McManus et al. (2009).

\section{Results}

\section{Sociodemographic factors and CMD}

Of the sample, $46.4 \%$ was female, and the mean age was 38.4 years. The prevalence of CMD in the last week was $14.1 \%$ (female $18.8 \%$, male $10.0 \%$ ) (Table 1 ). In comparison, the prevalence of CMD was $13.0 \%$ (female $17.0 \%$, male $11.0 \%$ ) in the working sample from the APMS 2000 (Stansfeld et al. 2011).

Logistic regression analysis revealed no significant associations between the sociodemographic variables of age, marital status, housing tenure, income, government region, education and CMD. However, women showed over twice the odds of CMD compared with men [OR 2.10, 95\% confidence interval (CI) 1.67-2.64]. Perceived support at work was associated with gender and age; effort/demand was associated with marital status and housing tenure. All subsequent analyses were therefore adjusted for age, gender, marital status and housing tenure. We did not adjust for education and income, as these are strongly related to SOC group and might thus be an over-adjustment.

\section{Major SOC groups and CMD}

Of the major SOC groups, personal service occupations had the highest prevalence of CMD (23.9\%, Table 1). The lowest prevalence was for process, plant and machine operatives $(7.5 \%)$. The ORs for CMD were raised significantly for personal service occupations relative to all other occupations, and this remained significant after adjustment for age, gender, housing tenure and marital status (OR 1.62, 95\% CI 1.11-2.37). Process, plant and machine operatives had a significantly reduced risk of CMD, but this became non-significant after adjustment for age, gender, housing tenure and marital status (Table 1). Further adjustment for alcohol-use disorders measured by the AUDIT did not change these ORs. After stratification by gender, the ORs for process, plant and machine operatives remained significantly reduced for men (OR 0.52, 95\% CI 0.28-0.99), but not for women. Female professional occupations also had a reduced risk of CMD (OR 0.66, 95\% CI 0.44-0.99). Personal service occupations had an increased risk among women that was maintained after full adjustment (OR $1.55,95 \%$ CI 1.02-2.36). Although the OR was also increased in men, this was not statistically significant.

\section{Sub-major SOC groups and CMD}

The prevalence and ORs for CMD for the sub-major SOC groups are shown in Table 1. In sub-major groups, the risk of CMD was increased in caring personal service occupations, maintained after full adjustment (OR 1.73, 95\% CI 1.16-2.58). There was no increased risk in leisure and other personal service occupations. Transport and machine drivers and operatives had a reduced risk of CMD relative to all other occupations (OR 0.34, 95\% CI 0.13-0.90), but this became non-significant after full adjustment.

\section{Major SOC groups and work characteristics}

Adverse work characteristics varied between major SOC groups (Table 2). Of the sample, $12.1 \%$ reported job strain, with rates ranging from $8.3 \%$ in professional occupations to $16.7 \%$ in skilled trade occupations. There was a linear relationship between effort/demands and major SOC group: those in the managerial and professional groups were most likely to report high effort/demands $(64.3 \%$ in managers and senior officials), and those in the largely manual occupations least likely to $(22.3 \%$ in sales and customer service occupations) and this was associated with statistically significant differences in risk. 
Managers and senior officials and professional occupations had a significantly lower risk of job strain but a higher risk of demands than all occupations together. Of the sample, $12.8 \%$ reported ERI. This ranged from $7.7 \%$ in sales and customer service occupations to $16.4 \%$ in associate professional and technical occupations. Low job security was reported by $30.9 \%$ of the sample, ranging from $41.2 \%$ in process plant and machine operatives to $23.8 \%$ in personal service occupations. Process, plant and machine operatives and elementary occupations had, as might be expected, a significantly higher risk of job insecurity compared with all occupations. No clear pattern emerged for levels of support between major SOC groups. Low support at work was reported by $26.1 \%$ of the sample, ranging from $36.3 \%$ in process, plant and machine operatives to $19.0 \%$ in personal service occupations. Personal service occupations had a lower risk of high demands, job insecurity and low social support compared with all other occupations.

\section{Do work characteristics explain major SOC group differences in CMD?}

We then examined whether work characteristics could explain the distribution of rates of CMD across the major SOC groups. Job strain, ERI, effort/demands, job security and social support at work were entered individually into models examining risks for CMD by SOC group (Table 3). After adjustment for job strain, in addition to age, gender, housing tenure and marital status the ORs for CMD related to personal service occupations actually increased by $11 \%$, remaining a significant predictor of CMD (OR 1.80, 95\% CI 1.222.66). Adjustment for ERI and effort/demands showed a similar increase in the OR for CMD in personal service occupations, but adjustment for low job security and low social support showed less increase in risk.

Men in personal service occupations showed an increase in the odds of CMD (OR 2.42, 95\% CI 1.00-5.87) when adjusted for job strain. The reduced odds for CMD among male process, plant and machine operatives was further reduced after adjustment for low job security and low social support at work.

The odds of CMD were also slightly raised in women in personal service occupations after adjustment for job strain (OR 1.68, 95\% CI 1.08-2.59). The effects of adjusting for the other work characteristics followed a fairly similar pattern in both men and women. Women in professional occupations showed a slightly greater reduction in risk of CMD (OR 0.65, $95 \%$ CI 0.44-0.97) after adjustment for job strain. Similar effects were seen in relation to ERI and to effort/demands. This protective effect diminished and became non-significant after adjustment for low social support at work.

In analyses stratified by gender, women in skilled trades showed a small diminution in the odds for CMD after adjusting for job strain, ERI, low job security and low social support but increased odds for CMD after adjustment for effort/demands (OR 2.60, 95\% CI 1.03-6.53). Women in elementary occupations (OR 1.79, 95\% CI 1.12-2.86) showed an increase in odds of CMD compared with all other occupations after adjustment for job strain, ERI, effort/demands and low job security.

\section{Sub-major groups}

Analysis of sub-major occupation groups showed that those in caring personal service occupations had an increased likelihood of suffering a CMD compared with all occupations. The magnitude of the odds increased slightly after adjustment for job strain, ERI, demands, job security and support at work (ORs ranged from 1.86 to 1.92). There were also increased odds of CMD in elementary administration and service occupations (OR 1.67, 95\% CI 1.08-2.58) and in sales occupations (OR 1.67, 95\% CI 1.08-2.58) after adjustment for effort/demands.

\section{Discussion}

\section{Strengths and limitations}

The APMS 2007 is a large and representative sample of the English adult population. Nevertheless, our study was faced with several limitations. Even in this relatively large sample, it was not possible to examine occupational groups in detail, particularly in some cases the breakdown of SOC groups by gender. Major SOC groups have adequate numbers, but are very broad, containing a variety of occupations whose work characteristics and work tasks will differ. This may make generalization to specific occupations difficult. The survey aimed to fulfil many purposes, so relatively few questions could be included on work characteristics. It did not measure duration of occupation, or whether participants had changed jobs recently. Finally, the cross-sectional design meant that directions of association are uncertain. Nevertheless, this is the first study to investigate whether adverse work characteristics can explain occupational differences in CMD in a nationally representative sample.

\section{Findings}

Personal service occupations stood out as having the greatest risk of CMD for both men and women. Among sub-major SOC groups the increased risk was 
confined to caring personal service occupations rather than leisure and other personal occupations. By contrast, male process plant and machine operatives had lower rates of disorder, as did women in professional occupations. In sub-major SOC groups lower rates were found in transport and mobile machine drivers and operatives.

There were fewer 'at-risk' occupations in the APMS 2007 than in the 2000 survey (J. Harris et al. unpublished observations). It may be that UK working conditions had improved during this period, which was prior to the current recession (Chandola, 2010). On the other hand, high-risk groups may be less represented, as numbers were somewhat smaller and the response rate lower in the APMS 2007. It also may be that many of the 'at-risk' jobs are now carried out in the 'black' or 'grey' economy and are not counted here.

Personal service occupations had high rates, both in the current, and in the 2000 survey. In the earlier survey there were also higher rates in clerical and secretarial and sales occupations, neither of which groups had significantly increased risk in the current survey, although male administrative and secretarial occupations had a higher risk of CMD, as did male sales and customer service occupations. Female rates were not raised for either of these two occupations. Plant and machine operatives in both surveys had a lower prevalence of CMD. The high rates of CMD in personal service occupations are also in keeping with other studies such as the SWI95 Study and the Danish Workforce Study (Jones et al. 1998; Wieclaw et al. 2005).

However, the prevalence of adverse psychosocial work characteristics did not follow the pattern of CMD by occupation. Process, plant and machine operatives had the lowest prevalence of disorder, but also the highest job strain, the lowest job security and the lowest social support at work. Likewise, despite low rates of CMDs, associate professional and technical occupations had the highest ERI, and managers and senior officials the highest demands. Neither did work characteristics explain the increased risk of CMDs associated with working in personal service occupations. Finally, again contrary to our hypothesis, adding job strain, ERI, demands, job security and social support at work individually to the analysis of occupational and CMD generally tended to increase the ORs rather than decrease them. It is possible that these changes simply represent random variation, but they did show a degree of consistency.

It should be noted that work characteristics have explained high rates of CMD in specific occupations in the French decennial health survey (Cohidon et al. 2010). So why was this not the case in the current study? There are several possible explanations, not necessarily mutually exclusive: our measures may not have been sufficiently sensitive, and findings may have been distorted by selection into and out of particular occupations. Moreover, it is possible that employees in different occupations interpret and rate the psychosocial work questions differently in relation to their occupational context, the views of their peers and the expectations and occupational culture. Individual attributes that might influence selection into occupations might also influence reporting of work characteristics.

Our job strain measures were necessarily brief, and work characteristics may not be evaluated in the same way by persons in different occupations. However, our use of these measures allowed us to corroborate the hypothesis that work characteristics are associated with CMD (Clark et al. 2012), so it seems likely that their inability to account for the association of occupation with CMD requires a different explanation. These analyses also demonstrated that work characteristics had effects on CMD that were independent of non-work stressors and levels of personal social support (Clark et al. 2012).

It should be noted that our questions on demand did not cover emotional demands. This may be particularly relevant for occupations such as caring personal service occupations. Many studies suggest that personal service occupations and other caring and teaching occupations are especially stressful (Jones et al. 1998; Cropley et al. 1999; Bultmann et al. 2001; Wieclaw et al. 2005). The high emotional demands, characteristic of these jobs, have been shown to be a risk factor for CMD (Hochschild, 1983; Wilhelm et al. 2004; Wieclaw et al. 2005). Caring personal service occupations include a range of occupations involved in caring for children, animals, the sick and the disabled (nursing auxiliaries, care assistants, residential wardens, nursery nurses, childminders, educational assistants and veterinary nurses). Nearly all include contact with the public as a prominent part of their jobs. Our high-risk jobs may therefore represent occupations with high levels of public contact that are stressful and a drain on emotional resources (Cherry et al. 2006; Hilton \& Whiteford, 2010). In contrast, jobs such as process plant and machine operatives typically involve restricted contact with the public outside the workforce. It is also possible that some jobs have inherently protective factors that we have not identified. It may be that we need more sophisticated measures of work characteristics to capture the complexity of how the work environment differs across occupations.

While some people may drift into a particular occupation, for most both the original decision to take a 
Table 3. Odds ratios for CMD by major SOC groups, additionally adjusted for work characteristics (job strain, effort-reward imbalance, job effort/demands, job security, social support at work) ${ }^{\mathrm{a}}$

\begin{tabular}{|c|c|c|c|c|c|}
\hline & $\begin{array}{l}\text { Adjusted for age, } \\
\text { gender, housing } \\
\text { tenure, marital status } \\
\text { and job strain }\end{array}$ & $\begin{array}{l}\text { Adjusted for age, } \\
\text { gender, housing } \\
\text { tenure, marital } \\
\text { status and ERI }{ }^{c}\end{array}$ & $\begin{array}{l}\text { Adjusted for age, } \\
\text { gender, housing tenure, } \\
\text { marital status and job } \\
\text { effort/demands }\end{array}$ & $\begin{array}{l}\text { Adjusted for age, } \\
\text { gender, housing } \\
\text { tenure, marital status } \\
\text { and job security }\end{array}$ & $\begin{array}{l}\text { Adjusted for age, } \\
\text { gender, housing tenure, } \\
\text { marital status and } \\
\text { social support at work }\end{array}$ \\
\hline & OR $(95 \% \mathrm{CI})$ & OR $(95 \% \mathrm{CI})$ & OR $(95 \% \mathrm{CI})$ & OR $(95 \% \mathrm{CI})$ & OR $(95 \% \mathrm{CI})$ \\
\hline \multicolumn{6}{|l|}{ Major SOC groups } \\
\hline \multicolumn{6}{|l|}{ Males and females $(n=3425)$} \\
\hline Managers and senior officials & $0.75(0.53-1.06)$ & $0.74(0.52-1.05)$ & $0.68(0.48-0.96)$ & $0.83(0.59-1.16)$ & $0.78(0.56-1.09)$ \\
\hline Professional occupations & $0.82(0.59-1.16)$ & $0.86(0.61-1.21)$ & $0.76(0.54-1.06)$ & $0.87(0.62-1.22)$ & $0.88(0.63-1.23)$ \\
\hline Associate professional and technical occupations & $0.92(0.67-1.27)$ & $0.90(0.65-1.25)$ & $0.90(0.66-1.23)$ & $0.98(0.71-1.35)$ & $1.03(0.76-1.39)$ \\
\hline Administrative and secretarial occupations & $0.95(0.67-1.35)$ & $0.93(0.66-1.33)$ & $0.95(0.67-1.35)$ & $0.92(0.65-1.30)$ & $0.92(0.65-1.30)$ \\
\hline Skilled trades occupations & $0.87(0.57-1.33)$ & $0.85(0.57-1.27)$ & $0.92(0.61-1.40)$ & $0.86(0.57-1.30)$ & $0.94(0.61-1.43)$ \\
\hline Personal service occupations & $1.80(1.22-2.66)^{*}$ & $1.89(1.27-2.81)^{*}$ & $1.82(1.24-2.68)^{*}$ & $1.75(1.18-2.60)^{*}$ & $1.73(1.18-2.54)^{*}$ \\
\hline Sales and customer service occupations & $1.25(0.81-1.95)$ & $1.26(0.82-1.94)$ & $1.36(0.88-2.11)$ & $1.14(0.74-1.75)$ & $1.09(0.71-1.67)$ \\
\hline Process, plant and machine operatives & $0.61(0.35-1.08)$ & $0.65(0.37-1.14)$ & $0.71(0.41-1.24)$ & $0.57(0.33-0.98)$ & $0.57(0.33-0.98)$ \\
\hline Elementary occupations & $1.36(0.91-2.04)$ & $1.34(0.90-1.99)$ & $1.52(1.03-2.24)^{*}$ & $1.25(0.85-1.83)$ & $1.23(0.84-1.79)$ \\
\hline \multicolumn{6}{|l|}{ Males $(n=1834)$} \\
\hline Managers and senior officials & $0.65(0.39-1.10)$ & $0.65(0.39-1.10)$ & $0.62(0.37-1.04)$ & $0.76(0.47-1.23)$ & $0.72(0.45-1.16)$ \\
\hline Professional occupations & $1.10(0.66-1.82)$ & $1.25(0.75-2.07)$ & $1.05(0.64-1.72)$ & $1.21(0.74-1.98)$ & $1.16(0.71-1.89)$ \\
\hline Associate professional and technical occupations & $1.14(0.67-1.93)$ & $1.20(0.70-2.04)$ & $1.12(0.66-1.90)$ & $1.22(0.71-2.10)$ & $1.23(0.74-2.06)$ \\
\hline Administrative and secretarial occupations & $1.74(0.87-3.46)$ & $1.74(0.87-3.48)$ & $1.75(0.88-3.48)$ & $1.82(0.90-3.66)$ & $1.83(0.93-3.60)$ \\
\hline Skilled trades occupations & $0.72(0.47-1.11)$ & $0.69(0.46-1.03)$ & $0.74(0.48-1.13)$ & $0.71(0.47-1.08)$ & $0.76(0.50-1.17)$ \\
\hline Personal service occupations & $2.42(1.00-5.87)^{*}$ & $2.52(1.03-6.14)^{*}$ & $2.37(0.98-5.72)$ & $2.49(0.99-6.26)$ & $2.17(0.89-5.28)$ \\
\hline Sales and customer service occupations & $1.84(0.90-3.79)$ & $1.69(0.80-3.55)$ & $1.93(0.93-4.01)$ & $1.73(0.84-3.54)$ & $1.53(0.74-3.18)$ \\
\hline Process, plant and machine operatives & $0.54(0.27-1.05)$ & $0.53(0.27-1.03)$ & $0.60(0.31-1.15)$ & $0.46(0.24-0.89)^{*}$ & $0.48(0.26-0.92)^{*}$ \\
\hline Elementary occupations & $1.18(0.63-2.23)$ & $1.08(0.57-2.05)$ & $1.23(0.67-2.26)$ & $0.94(0.51-1.76)$ & $1.01(0.55-1.85)$ \\
\hline \multicolumn{6}{|l|}{ Females $(n=1591)$} \\
\hline Managers and senior officials & $0.84(0.56-1.25)$ & $0.83(0.56-1.25)$ & $0.73(0.49-1.10)$ & $0.90(0.61-1.35)$ & $0.85(0.56-1.28)$ \\
\hline Professional occupations & $0.65(0.44-0.97)^{*}$ & $0.64(0.43-0.96)^{*}$ & $0.59(0.40-0.87)^{*}$ & $0.67(0.45-1.00)$ & $0.68(0.45-1.03)$ \\
\hline Associate professional and technical occupations & $0.82(0.59-1.15)$ & $0.77(0.55-1.10)$ & $0.80(0.57-1.11)$ & $0.87(0.62-1.22)$ & $0.91(0.65-1.26)$ \\
\hline Administrative and secretarial occupations & $0.78(0.54-1.12)$ & $0.75(0.52-1.08)$ & $0.77(0.54-1.10)$ & $0.73(0.51-1.05)$ & $0.74(0.52-1.06)$ \\
\hline Skilled trades occupations & $2.16(0.85-5.48)$ & $2.03(0.80-5.11)$ & $2.60(1.03-6.53)^{*}$ & $2.02(0.82-4.95)$ & $2.24(0.88-5.68)$ \\
\hline Personal service occupations & $1.68(1.08-2.59)^{*}$ & $1.77(1.14-2.73)^{*}$ & $1.71(1.12-2.63)^{*}$ & $1.64(1.07-2.52)^{*}$ & $1.68(1.09-2.57)^{*}$ \\
\hline
\end{tabular}


Sales and customer service occupations

Process, plant and machine operatives

Elementary occupations

Sub-major SOC groups

Males and females $(n=3425)$

Corporate managers

Science and technology professionals

Health professionals

Teaching and research professionals

Science and technology associate professionals

Health and social welfare associate professionals

Protective service occupations

Culture media sports occupations

Business and public service associate professionals

Administrative occupations

Secretarial and related occupations

Skilled agricultural trades

Skilled construction and building trades

Textiles printing and other skilled trades

Caring personal service occupations

Leisure and other personal service occupations

Sales occupations

Customer service occupation

Process plant and machine operatives

Transport and mobile machine drivers and operatives

Elementary trades, plant and storage-related occupation

Elementary administration and service occupations
Managers and proprietors in agriculture and service

Business and public service professionals

Skilled metal and electrical trades

\begin{tabular}{|c|c|c|c|c|}
\hline $1.02(0.60-1.73)$ & $1.07(0.65-1.78)$ & $1.14(0.67-1.92)$ & $0.95(0.57-1.60)$ & $0.94(0.57-1.57)$ \\
\hline $1.01(0.40-2.55)$ & $1.13(0.45-2.83)$ & $1.17(0.47-2.89)$ & $0.96(0.40-2.33)$ & $0.90(0.38-2.18)$ \\
\hline $1.48(0.93-2.38)$ & $1.57(0.98-2.49)$ & $1.79(1.12-2.86)^{*}$ & $1.48(0.94-2.32)^{*}$ & $1.41(0.89-2.21)$ \\
\hline $0.83(0.58-1.17)$ & $0.81(0.57-1.15)$ & $0.74(0.52-1.05)$ & $0.89(0.63-1.26)$ & $0.85(0.61-1.20)$ \\
\hline $0.49(0.22-1.10)$ & $0.51(0.21-1.21)$ & $0.48(0.22-1.08)$ & $0.58(0.26-1.30)$ & $0.51(0.23-1.15)$ \\
\hline $0.82(0.45-1.50)$ & $0.82(0.43-1.56)$ & $0.78(0.42-1.45)$ & $0.81(0.44-1.50)$ & $0.88(0.47-1.62)$ \\
\hline $1.58(0.48-5.19)$ & $1.50(0.45-5.00)$ & $1.45(0.44-4.74)$ & $1.45(0.44-4.75)$ & $1.49(0.47-4.71)$ \\
\hline $0.92(0.57-1.47)$ & $0.99(0.61-1.58)$ & $0.84(0.52-1.34)$ & $1.05(0.66-1.67)$ & $1.01(0.64-1.62)$ \\
\hline $0.57(0.26-1.23)$ & $0.58(0.26-1.26)$ & $0.52(0.24-1.13)$ & $0.55(0.25-1.21)$ & $0.56(0.26-1.20)$ \\
\hline $1.44(0.61-3.37)$ & $1.58(0.68-3.69)$ & $1.45(0.63-3.32)$ & $1.67(0.71-3.91)$ & $1.65(0.71-3.79)$ \\
\hline $0.69(0.43-1.10)$ & $0.60(0.38-0.96)$ & $0.67(0.42-1.07)$ & $0.70(0.44-1.12)$ & $0.83(0.53-1.29)$ \\
\hline $1.48(0.71-3.05)$ & $1.61(0.78-3.33)$ & $1.52(0.74-3.11)$ & $1.69(0.81-3.55)$ & $1.82(0.88-3.75)$ \\
\hline $1.20(0.49-2.94)$ & $1.11(0.45-2.76)$ & $1.13(0.46-2.76)$ & $1.25(0.51-3.07)$ & $1.14(0.48-2.71)$ \\
\hline $0.89(0.55-1.44)$ & $0.92(0.55-1.54)$ & $0.86(0.53-1.39)$ & $0.92(0.55-1.56)$ & $0.90(0.56-1.47)$ \\
\hline $0.99(0.66-1.47)$ & $0.93(0.63-1.39)$ & $0.98(0.66-1.47)$ & $0.97(0.65-1.44)$ & $1.00(0.67-1.49)$ \\
\hline $0.88(0.45-1.70)$ & $0.95(0.48-1.87)$ & $0.88(0.46-1.71)$ & $0.82(0.42-1.58)$ & $0.76(0.39-1.47)$ \\
\hline $1.31(0.28-6.20)$ & $1.32(0.28-6.17)$ & $1.29(0.27-6.23)$ & $0.94(0.21-4.17)$ & $0.94(0.23-3.78)$ \\
\hline $0.82(0.48-1.42)$ & $0.80(0.47-1.35)$ & $0.87(0.51-1.49)$ & $0.88(0.51-1.50)$ & $0.95(0.55-1.66)$ \\
\hline $1.01(0.37-2.79)$ & $0.95(0.37-2.42)$ & $1.03(0.38-2.80)$ & $0.92(0.35-2.45)$ & $0.96(0.34-2.71)$ \\
\hline $0.83(0.39-1.75)$ & $0.84(0.41-1.73)$ & $0.91(0.43-1.90)$ & $0.83(0.40-1.73)$ & $0.91(0.43-1.94)$ \\
\hline $1.92(1.27-2.91)^{*}$ & $1.99(1.31-3.02)^{*}$ & $1.92(1.28-2.88)^{*}$ & $1.86(1.24-2.81)^{*}$ & $1.86(1.25-2.77)^{*}$ \\
\hline $1.11(0.38-3.24)$ & $1.26(0.41-3.87)$ & $1.18(0.39-3.59)$ & $1.12(0.36-3.48)$ & $1.04(0.35-3.16)$ \\
\hline $1.50(0.96-2.34)$ & $1.50(0.97-2.33)$ & $1.67(1.08-2.58)$ & $1.34(0.88-2.04)$ & $1.31(0.87-1.99)$ \\
\hline $1.03(0.45-2.36)$ & $0.93(0.43-2.01)$ & $1.10(0.48-2.54)$ & $1.01(0.41-2.46)$ & $0.98(0.41-2.34)$ \\
\hline $0.72(0.37-1.39)$ & $0.77(0.40-1.51)$ & $0.84(0.44-1.62)$ & $0.66(0.35-1.25)$ & $0.70(0.37-1.30)$ \\
\hline $0.48(0.19-1.26)$ & $0.49(0.19-1.27)$ & $0.55(0.21-1.42)$ & $0.46(0.18-1.18)$ & $0.42(0.16-1.09)$ \\
\hline $0.90(0.38-2.12)$ & $0.85(0.36-2.01)$ & $0.99(0.43-2.28)$ & $0.92(0.40-2.09)$ & $0.91(0.40-2.08)$ \\
\hline $1.50(0.96-2.34)$ & $1.50(0.97-2.33)$ & $1.67(1.08-2.58)^{*}$ & $1.34(0.88-2.04)$ & $1.31(0.87-1.99)$ \\
\hline
\end{tabular}

CMD, Common mental disorder; SOC, Standard Occupational Classification; ERI, effort-reward imbalance; OR, odds ratio; CI, confidence interval.

Data are given OR $(95 \% \mathrm{CI})$

a Adjusted analysis is adjusted for age, gender, housing tenure and marital status. Dependent variable CMD, reference group is no CMD; independent variable SOC group, reference group is all other occupations.

b Karasek Job Content Instrument (Karasek, 1979; Karasek \& Theorell, 1990).

c Effort Reward Imbalance questionnaire (Siegrist et al. 2009).

$* p \leqslant 0.05$. 
job, and the subsequent commitment to it are active. Thus, another interpretation of our results is that high rates of CMD represent selection into occupations for people with a high risk of CMD. Kohn \& Schooler (1982) have shown both that personality has an important effect on the choice of a particular occupation (see also Firth-Cozens et al. 1999), and that job conditions influence personality. Similarly, Ezoe et al. (1994) found that schizotypal and avoidant traits were more frequent in computer engineers than clerical workers in the same firm, irrespective of length of service, suggesting that people with these personality traits may preferentially select occupations requiring little contact with people. Selection may also apply to the domestic sphere and the risks associated with selection at work may be linked to similar risks of CMD at home. The effect of decisions to move out of particular occupations is likely to be complex. People who remain in the job over a long period may do so because they have a high tolerance of stress and are therefore less likely to suffer adverse effects. However, there may also be differential selection out of high-stress occupations by people who are most able to move away to jobs with more desirable characteristics. As a result, some of those left behind because they are less able to move may be more at risk of CMD. Because of this complexity, it seems unlikely that selection according to personality is a complete explanation for the higher rates of CMD in these occupations.

For further scientific advance in this field, the importance of this study is trying to match self-report of adverse psychosocial working conditions with the rates of CMDs within occupations. As these do not match in this study the findings suggest that current accounts of psychosocial stressors at work are incomplete and need to be further developed. Despite our inability to explain the occupational differences in CMD in terms of work characteristics, the latter were clearly associated overall with CMD (Clark et al. 2012). There is thus a particular need for replication of the results presented here before definitive conclusions can be drawn.

\section{Acknowledgements}

The APMS 2007 was commissioned by the National Health Service Information Centre for Health and Social Care with funding from the Department of Health. These analyses were funded by a grant from the Health and Safety Executive and the Department for Work and Pensions. Ethical approval for the APMS 2007 was obtained from the Royal Free Hospital and Medical School Research Ethics Committee (reference no. 06/Q0501/71).

\section{Declaration of Interest}

S.M. and J.H. are employed by the National Centre for Social Research, the primary contractor for the APMS 2007.

\section{References}

Bonde JPE (2008). Psychosocial factors at work and risk of depression: a systematic review of the epidemiological evidence. Occupational and Environmental Medicine 65, 438-445.

Bultmann U, Kant I, Van Amelsvoort LGPM, van den Brandt PA, Kasl SV (2001). Differences in fatigue and psychological distress across occupations: results from The Maastricht Cohort Study of Fatigue at Work. Journal of Occupational and Environmental Medicine 43, 976-983.

Chandola T (2010). Stress at Work. British Academic Policy Centre: London.

Cherry NM, Chen Y, McDonald JC (2006). Reported incidence and precipitating factors of work-related stress and mental ill-health in the United Kingdom (1996-2001). Occupational Medicine (London) 56, 14-21.

Clark C, Pike C, McManus S, Harris J, Bebbington P, Brugha T, Jenkins R, Meltzer H, Weich S, Stansfeld S (2012). The contribution of work and non-work stressors to common mental disorders in the 2007 Adult Psychiatric Morbidity Survey. Psychological Medicine 42, 829-842.

Cohidon C, Santin G, Imbernon E, Goldberg M (2010). Working conditions and depressive symptoms in the 2003 decennial health survey: the role of occupational category. Social Psychiatry and Psychiatric Epidemiology 45, 1135-1147.

Cropley M, Steptoe A, Joekes K (1999). Job strain and psychiatric morbidity. Psychological Medicine 29, 1411-1416.

de Jonge J, Bosma H, Peter R, Siegrist J (2000). Job strain, effort-reward imbalance and employee well-being: a large-scale cross-sectional study. Social Science and Medicine 50, 1317-1327.

de Lange AH, Taris TW, Kompier MA, Houtman IL, Bongers PM (2003). The very best of the millennium: longitudinal research and the demand-control-(support) model. Journal of Occupational Health Psychology 8, 282-305.

Eaton WW, Anthony JC, Mandel W, Garrison R (1990). Occupations and the prevalence of major depressive disorder. Journal of Occupational Medicine 32, 1079-1087.

Ezoe S, Araki S, Ono Y, Kawakami N, Murata K (1994). Assessment of personality traits and psychiatric symptoms in workers in a computer manufacturing plant in Japan. American Journal of Industrial Medicine 25, 187-196.

Firth-Cozens J, Lema VC, Firth RA (1999). Specialty choice, stress and personality: their relationships over time. British Journal of Hospital Medicine 60, 751-755.

Hilton MF, Whiteford HA (2010). Interacting with the public as a risk factor for employee psychological distress. BMC Public Health 10, 435.

Hochschild AR (1983). The Managed Heart: Commercialization of Human Feeling. University of California Press: Berkeley.

Jenkins R, Meltzer H, Bebbington P, Brugha T, Farrell M, McManus S, Singleton N (2009). The British Mental 
Health Survey Programme: achievements and latest findings. Social Psychiatry and Psychiatric Epidemiology 44, 899-904.

Johnson JV, Hall EM (1988). Job strain, work place social support, and cardiovascular disease: a cross-sectional study of a random sample of the Swedish working population. American Journal of Public Health 78, 1336-1342.

Jones JT, Hodgson JT, Clegg TA, Elliott RC (1998). Self-Reported Work-Related Illness in 1995: Results of a Household Survey. HSE Books: Sudbury.

Karasek R (1979). Job demands, job decision latitude, and mental strain: implications for job redesign. Administrative Science Quarterly 24, 285-309.

Karasek R, Theorell T (1990). Healthy Work: Stress, Productivity and the Reconstruction of the Working Life. Basic Books: New York.

Kish L (1965). Survey Sampling. John Wiley \& Sons, Inc. : New York.

Kohn ML, Schooler C (1982). Job conditions and personality: a longitudinal assessment of their reciprocal effects. American Journal of Science 87, 1257-1286.

Lewis G, Pelosi AJ, Araya R, Dunn G (1992). Measuring psychiatric disorder in the community: a standardized assessment for use by lay interviewers. Psychological Medicine 22, 465-486.

Marchand A (2007). Mental health in Canada: are there any risky occupations and industries? International Journal of Law and Psychiatry 30, 272-283.

McManus, S, Meltzer H, Brugha T, Bebbington P, Jenkins R (eds) (2009). Adult Psychiatric Morbidity in England 2007: Results of a Household Survey. NHS Information Centre: Leeds.

Netterstrom B, Conrad N, Bech P, Fink P, Olsen O, Rugulies R, Stansfeld S (2008). The relation between work-related psychosocial factors and the development of depression. Epidemiologic Reviews 30, 118-132.

North FM, Syme SL, Feeney A, Shipley M, Marmot M (1996). Psychosocial work environment and sickness absence among British civil servants: the Whitehall II study. American Journal of Public Health 86, 332-340.

Office for National Statistics (2000). Standard Occupational Classification 2000. Volume 1: Structure and Descriptions of Unit Groups. The Stationery Office: London.

Pikhart H, Bobak M, Pajak A, Malyutina S, Kubinova R, Topor R, Sebakova H, Nikitin Y, Marmot M (2004).
Psychosocial factors at work and depression in three countries of Central and Eastern Europe. Social Science and Medicine 58, 1475-1482.

Roberts RE, Lee ES (1993). Occupation and the prevalence of major depression, alcohol, and drug abuse in the United States. Environmental Research 61, 266-278.

Sanne B, Mykletun A, Dahl AA, Moen BE, Tell GS (2003). Occupational differences in levels of anxiety and depression: the Hordaland Health Study. Journal of Occupational and Environmental Medicine 45, 628-638.

Saunders JB, Aasland OG, Babor TF, Dela Fuente JR, Grant M (1993). Development of the Alcohol Use Disorders Identification Test (AUDIT): WHO collaborative project on early detection of persons with harmful alcohol consumption, part II. Addiction 88, 791-804.

Siegrist J (1996). Adverse health effects of high-effort/lowreward conditions. Journal of Occupational Health Psychology 1, 27-41.

Siegrist J (2008). Chronic psychosocial stress at work and risk of depression: evidence from prospective studies. European Archives of Psychiatry and Clinical Neuroscience 258, S115-S119.

Siegrist J, Wege N, Puhlhofer F, Wahrendorf M (2009). A short generic measure of work stress in the era of globalization: effort-reward imbalance. International Archives of Occupational and Environmental Health 82, 1005-1013.

Stansfeld S, Candy B (2006). Psychosocial work environment and mental health - a meta-analytic review. Scandinavian Journal of Work, Environment and Health 32, 443-462.

Stansfeld SA, Rasul FR, Head J, Singleton N (2011). Occupation and mental health in a national UK survey. Social Psychiatry and Psychiatric Epidemiology 46, 101-110. van Vegchel N, de Jonge J, Bosma H, Schaufeli W (2005). Reviewing the effort-reward imbalance model: drawing up the balance of 45 empirical studies. Social Science and Medicine 60, 1117-1131.

Wieclaw J, Agerbo E, Mortensen PB, Bonde JP (2005). Occupational risk of affective and stress-related disorders in the Danish workforce. Scandinavian Journal of Work, Environment and Health 31, 343-351.

Wilhelm K, Kovess V, Rios-Seidel C, Finch A (2004). Work and mental health. Social Psychiatry and Psychiatric Epidemiology 39, 866-873. 